\title{
Effect of Pregnancy on Quantitative Medication Use and Relation to Exacerbations in Asthma
}

\author{
So-My Koo, ${ }^{1,2}$ Yunsun Kim, ${ }^{2}$ Chorong Park, ${ }^{2}$ Gun Woo Park, ${ }^{3}$ MoonGyu Lee, ${ }^{3}$ \\ Sungho Won, ${ }^{3,4,5}$ and Hyeon-Jong Yang ${ }^{2,6}$ \\ ${ }^{1}$ Division of Allergy and Respiratory Medicine, Department of Internal Medicine, Soonchunhyang University Seoul Hospital, \\ Soonchunhyang University College of Medicine, Seoul, Republic of Korea \\ ${ }^{2}$ SCH Biomedical Informatics Research Unit, Soonchunhyang University Seoul Hospital, Seoul, Republic of Korea \\ ${ }^{3}$ Department of Public Health Science, Graduate School of Public Health, Seoul National University, Seoul, Republic of Korea \\ ${ }^{4}$ Interdisciplinary Program of Bioinformatics, Seoul National University, Seoul, Republic of Korea \\ ${ }^{5}$ Institute of Health and Environment, Seoul National University, Seoul, Republic of Korea \\ ${ }^{6}$ Pediatric Allergy and Respiratory Center, Department of Pediatrics, Soonchunhyang University Seoul Hospital, \\ Soonchunhyang University College of Medicine, Seoul, Republic of Korea
}

Correspondence should be addressed to Sungho Won; sunghow@gmail.com and Hyeon-Jong Yang; pedyang@schmc.ac.kr

Received 14 March 2017; Revised 23 May 2017; Accepted 12 June 2017; Published 20 July 2017

Academic Editor: Kyung S. Lee

Copyright (C) 2017 So-My Koo et al. This is an open access article distributed under the Creative Commons Attribution License, which permits unrestricted use, distribution, and reproduction in any medium, provided the original work is properly cited.

Background. The quantification of asthma medication reduction and its relation to an aggravation of asthma during pregnancy at an individual level are unclear. Methods. We conducted a nationwide retrospective cohort study of asthmatic pregnant women in South Korea. All of the asthma medications were ranked from 1 to 4 according to the guideline-based stepwise approach. We assessed the daily sums of the ranks of the asthma medications and their association with exacerbations during three phases based on the individual's delivery date: before, during, and after pregnancy. Results. The study cohort included 115,169 asthmatic pregnant women who gave birth between 2011 and 2013. The subjects were clustered into four groups according to the daily rank sums of their asthma medication. Asthma medications were rapidly reduced at the beginning of the pregnancy and then slowly increased after delivery. Exacerbations were more frequent in the group with higher rank-sum values than in the group with lower values. Overall exacerbations were reduced during pregnancy compared to before or after delivery. Conclusions. Asthmatic pregnant women tended to reduce their asthma medication use during pregnancy. This led to a greater number of exacerbations in a small part of the study population.

\section{Introduction}

Pregnancy affects the severity and control of asthma and is one of the most important risk factors for the exacerbation of asthma [1]. The prevalence of asthma during pregnancy is known to be $3 \%-12 \%[2,3]$, and the rate of women requiring medical intervention due to exacerbation during pregnancy is about $20 \%$ [4]. It is well known that the maintenance of asthma therapy during pregnancy outweighs the risk to the fetus $[5,6]$. Poorly controlled asthma can have a negative effect on pregnant women and fetuses. Asthma exacerbations increase the risk of a preterm delivery, low birth weight, perinatal mortality, and preeclampsia [1, 7]. Indeed, several reports have shown that fetal anomalies are likely to be associated with asthma exacerbations rather than the use of asthma medication during pregnancy $[8,9]$, and international guidelines consistently recommend the continuation of asthma medication during pregnancy. However, despite this, most studies have consistently reported that asthmatic women during pregnancy tend to stop or switch their asthma medication due to concerns regarding adverse effects on the fetus [10-14]. Some studies have suggested that the severity of asthma increases the exacerbation rate $[4,15]$, and the severity of asthma before pregnancy is 


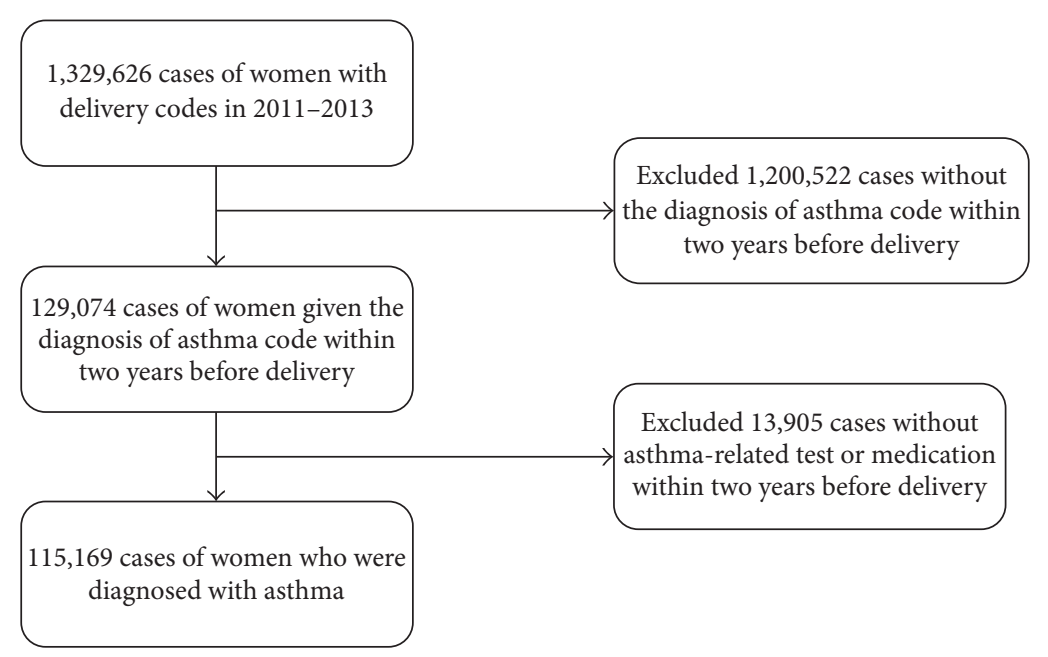

FIgURE 1: Flow diagram of the study cohort.

related to subsequent exacerbations during pregnancy and asthma symptoms during labor and delivery [4]. Therefore, severe asthma should be closely monitored and adequately controlled during pregnancy.

It is well known that one-third of pregnant women with asthma experience worsened symptoms, another third improve, and the others show no change [16, 17]. Stopping or poor compliance with asthma medication may aggravate asthma in pregnancy. On the other hand, previous severe asthma can nevertheless aggravate asthma symptoms without the patient stopping their asthma medication, and naturally improved asthma during pregnancy may be well controlled despite discontinuing with asthma controllers. Most of the previous studies have, however, investigated patterns of prescriptions and asthma symptoms at the population level but not at the individual level. To the best of our knowledge, no studies have investigated changes at the level of asthma medications and their correlations with asthma exacerbations before, during, and after pregnancy at the individual level. For this reason, further study is needed to evaluate the effect of pregnancy on medication use and its correlation with asthma exacerbation at the individual level. We hypothesized that asthmatic women tend to reduce or stop the use of asthma medication during pregnancy and that the correlation with asthma exacerbation will differ according to their severity of asthma and its natural course before and during pregnancy. To prove this hypothesis, we conducted a nationwide population-based cohort study to evaluate the quantitative changes in asthma medication during three phases of pregnancy (before, during, and after pregnancy) and their correlation with asthma exacerbation.

\section{Methods}

2.1. Data Sources. The Health Insurance Review and Assessment Service (HIRA; Wonju, Republic of Korea), a government-affiliated agency responsible for examining the accuracy of claims for National Health Insurance and National Medical Aid in South Korea, covers approximately 96.6\% of the South Korean population [14]. The HIRA database includes reviewed information regarding demographics, medical healthcare service data including a set of diagnostic codes (International Statistical Classification of Disease and Related Health Problems, 10th Edition; ICD-10), dispensed prescribed medications, and diagnostic tests and procedures. In particular, it includes all information on hospital stays, emergency department (ED) visits, and outpatient clinic visits. Missing or aberrant values in key fields such as drug name, quantity, date dispensed, and duration comprise under $0.5 \%$ of all records [18]. We used the HIRA database to conduct a nationwide populationbased observational retrospective cohort study of asthmatic pregnant women.

2.2. Study Subjects and Design. A total of 1,329,626 women assigned a delivery code were identified by a review of the HIRA data for the period of January 1, 2011, to December 31, 2013. Among them, 115,169 asthmatic pregnant women were identified who met all of the following criteria: (1) a delivery between January 1, 2011, and December 31, 2013; (2) a diagnosis code for asthma according to the ICD-10 J45.xJ46.x code set within two years before the delivery date; and (3) being prescribed asthma medication or undergoing diagnostic tests for asthma at least once within two years before the delivery date (Figure 1). Detailed information regarding asthma medications is described below, and diagnostic tests for asthma included spirometry with or without a bronchodilator response and bronchial provocation tests. The observation period was divided into three phases: 1 year (365 days) before pregnancy, during pregnancy (280 days) before the delivery date, and 1 year (365 days) after pregnancy. The delivery dates were determined from the procedure codes related to delivery. Daily asthma medications, asthma exacerbations, and healthcare utilization were observed from one year before pregnancy to one year after delivery (Figure 2). 


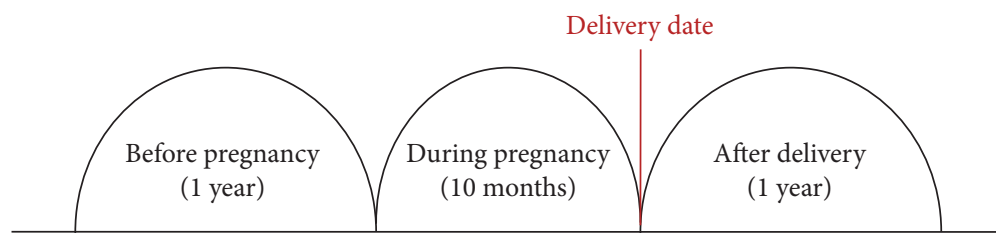

FIGURE 2: Schematic diagram of the three phases of observation.

2.3. Asthma Medications and Their Quantitative Rank. The asthma medications were defined as inhaled corticosteroids (ICSs), ICS combined with inhaled long-acting $\beta_{2}$-agonists (ICS/LABAs), inhaled short-acting $\beta_{2}$-agonists (SABAs), LABAs, long-acting muscarinic antagonists (LAMAs), oral leukotriene receptor antagonists (LTRAs), xanthine derivatives, and systemic corticosteroids. Daily asthma medications, based on the codes for prescribed and dispensed medications, were captured through the three phases of pregnancy and were ranked from the level of controller as classified by the Global Initiative for Asthma guidelines with respect to the stepwise approach [19]. Low-dose ICSs [2023], LTRAs [24], xanthine [25], or LABAs [26] were defined as rank 1, medium- to high-dose ICS [27, 28] or low-dose ICS/LABA combination [29] inhalers as rank 2, and mediumto high-dose ICS/LABA combination [30] inhalers as rank 3. Rank 4 was defined as any of the following: (1) LAMA [31] inhaler and (2) long-term use of oral prednisolone of less than $20 \mathrm{mg}$ or other types of corticosteroids [32] with the same potency (betamethasone at $2.4 \mathrm{mg}$, dexamethasone at $3 \mathrm{mg}$, or methylprednisolone at $16 \mathrm{mg}$ ) (Table 1). We calculated the daily rank of asthma medications at the individual level. If subjects took more than or equal to two different asthma medications at the same time, the sums of their ranks were added up to a maximum of rank 4. ICSs were marked as their ranks for each consecutive day they were taken (e.g., LTRA and low-dose ICS were ranked as 1 and 60 doses of ICS used twice daily ranked as 1 for 30 days). The standard ICS/LABA inhaler contains 60 doses for use over 30 days (Table 1). The rank-sum values of the asthma medications were plotted for each patient to indicate time-varying patterns. Corticosteroid burst therapy and SABAs were not ranked but were defined as a mark of asthma exacerbation.

2.4. Definition of Asthma Exacerbations. Asthma exacerbations were defined as one of the ICD-10 asthma codes along with urgent events satisfying the following conditions occurring on the same date: asthma-related outpatient clinic visit with systemic corticosteroid burst, as mentioned above (i.e., more than $20 \mathrm{mg}$ of prednisolone or other types of corticosteroids with the same potency); asthma-related hospitalization; asthma-related ED visit; or outpatient clinic visit with SABA nebulizer treatment under the ICD-10 asthma codes.

2.5. Healthcare Utilization. The daily records relating to healthcare use were reviewed and classified as hospital stay, ED visit, and outpatient clinic visit. Furthermore, outpatient clinic visits were subdivided according to their specialty, for example, internal medicine, obstetrics/gynecology, general practitioner, general surgery, otolaryngology, and family medicine.

2.6. Ethical Considerations. The research protocol for this study was approved by the Ethical Review Board of Soonchunhyang University Seoul Hospital (approval number: SCHUH 2016-04-024).

2.7. Definition of Clustered Groups. Study subjects were clustered into groups according to their pattern of asthma medication using the statistical methods detailed below.

2.8. Statistical Analyses. Rank-sum values of the asthma medications for each subject were calculated every month and the overall trends during that time were visualized with a spaghetti plot. Additionally, the proportions of subjects who experienced asthma exacerbations for one year before, during, and one year after pregnancy were also calculated. In total, subjects were followed up for 1,010 days. Continuous variables, such as the prescribed and dispensed amounts of asthma medications and the number of asthma exacerbations and healthcare utilization, are presented as means \pm standard deviations. Monthly rank-sum values of the asthma medications for one year before, during, and one year after pregnancy were calculated for each subject and compared with a multivariate analysis of variance to detect whether asthma medication use was affected by pregnancy. The ranksum values were also used for clustering with the $k$-means algorithm. The $k$-means algorithm was performed using Euclidean distances calculated from three rank-sum values for one year before, during, and one year after pregnancy and the number of clusters was determined by $r^{2}$, which is defined as the "sum of squares between" over the "sum of squares total." These analyses were conducted with PROC FASTCLUS and subjects were clustered into four groups. For each group, all statistical analyses were conducted to detect the pattern of drugs related to asthma exacerbations.

Associations between the daily rank-sum values of the asthma medications and asthma exacerbations were analyzed with a quasi-likelihood-based approach. Analyses were conducted with PROC GLIMMIX (SAS version 6.1). For each subject, the number of asthma exacerbations was counted during pregnancy and was used as a response variable. It should be noted that the response variables have very large values and were thus assumed to follow a quasi-Poisson distribution. The logarithm was used as a link function, and this will be referred to as a quasi-Poisson regression for the remainder of this report. The rank-sum values of the asthma 
TABLE 1: Ranking of asthma medication according to the guideline-based stepwise approach.

\begin{tabular}{|c|c|c|c|}
\hline Component & Type & Rank & Prescription period \\
\hline \multicolumn{4}{|l|}{ LTRAs } \\
\hline Montelukast & Oral & 1 & 1 \\
\hline Pranlukast & Oral & 1 & 1 \\
\hline Zafirlukast & Oral & 1 & 1 \\
\hline \multicolumn{4}{|l|}{ Xanthine } \\
\hline Aminophylline & Oral & 1 & 1 \\
\hline Theophylline & Oral & 1 & 1 \\
\hline \multicolumn{4}{|l|}{ LABA } \\
\hline Bambuterol & Oral & 1 & 1 \\
\hline Fenoterol & Oral & 1 & 1 \\
\hline Formoterol & Oral & 1 & 1 \\
\hline Procaterol & Oral & 1 & 1 \\
\hline Procaterol & Inhaler & 1 & 30 \\
\hline Terbutaline & Oral & 1 & 1 \\
\hline \multicolumn{4}{|l|}{ ICS } \\
\hline \multicolumn{4}{|l|}{ Low-dose ICS } \\
\hline Budesonide & Inhaler & 1 & 30 \\
\hline Ciclesonide & Inhaler & 1 & 30 \\
\hline Fluticasone propionate & Inhaler & 1 & 30 \\
\hline \multicolumn{4}{|l|}{ Medium- to high-dose ICS } \\
\hline Budesonide & Inhaler & 2 & 30 \\
\hline Fluticasone propionate & Inhaler & 2 & 30 \\
\hline \multicolumn{4}{|l|}{ ICS/LABA } \\
\hline \multicolumn{4}{|l|}{ Low-dose ICS/LABA } \\
\hline Budesonide/formoterol & Inhaler & 2 & 30 \\
\hline Budesonide/formoterol $^{*}$ & Inhaler & 2 & $60^{*}$ \\
\hline Beclomethasone dipropionate/formoterol & Inhaler & 2 & 30 \\
\hline Fluticasone furoate/vilanterol & Inhaler & 2 & 30 \\
\hline Fluticasone propionate/formoterol & Inhaler & 2 & 30 \\
\hline Fluticasone propionate/salmeterol & Inhaler & 2 & 30 \\
\hline Fluticasone propionate/salmeterol ${ }^{* *}$ & Inhaler & 2 & $14^{* *}$ \\
\hline \multicolumn{4}{|l|}{ Medium- to high-dose ICS/LABA } \\
\hline Budesonide/formoterol & Inhaler & 3 & 30 \\
\hline Fluticasone propionate/salmeterol & Inhaler & 3 & 30 \\
\hline Fluticasone propionate/salmeterol ${ }^{* *}$ & Inhaler & 3 & $14^{* *}$ \\
\hline Fluticasone propionate/formoterol & Inhaler & 3 & 30 \\
\hline Fluticasone furoate/vilanterol & Inhaler & 3 & 30 \\
\hline \multicolumn{4}{|l|}{ LAMA } \\
\hline Tiotropium & Inhaler & 4 & 30 \\
\hline \multicolumn{4}{|l|}{ Systemic corticosteroids } \\
\hline Betamethasone $<2.4 \mathrm{mg}$ & & 4 & 1 \\
\hline Dexamethasone $<3 \mathrm{mg}$ & & 4 & 1 \\
\hline Methylprednisolone $<16 \mathrm{mg}$ & & 4 & 1 \\
\hline Prednisolone $<20 \mathrm{mg}$ & & 4 & 1 \\
\hline
\end{tabular}

${ }^{*}$ The device contains 120 doses, twice the dose of the standard device. ${ }^{* *}$ The device contains 28 doses for use over 14 days; LTRA, leukotriene receptor antagonist; LABA, long-acting $\beta_{2}$-agonists; ICS, inhaled corticosteroid; LAMA, long-acting muscarinic antagonists. 


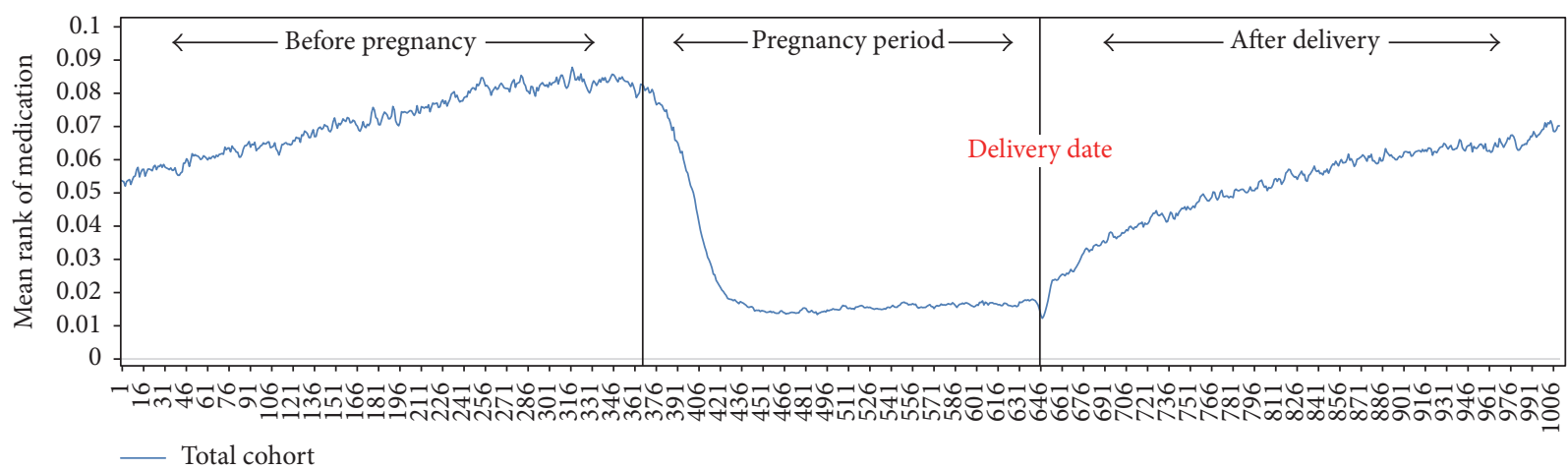

Figure 3: Daily rank-sum values of asthma medications during the time periods. The overall rank-sum value of the asthma medications tended to be abruptly reduced at the beginning of pregnancy compared with before and slowly increased after pregnancy.

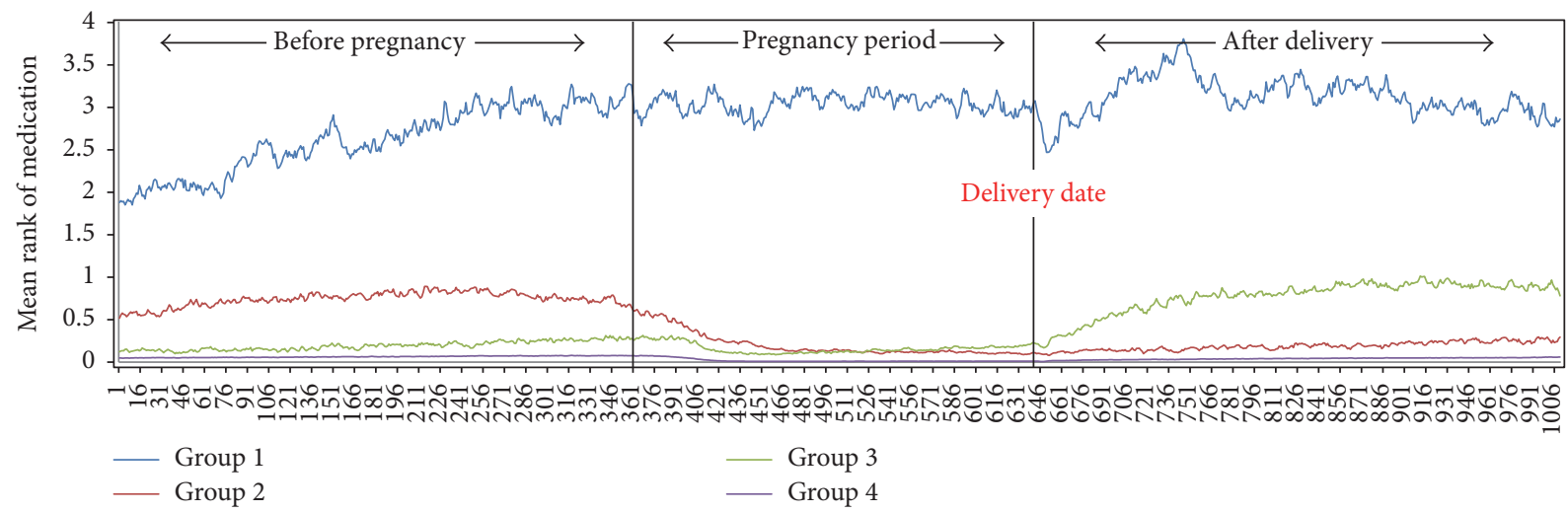

FIGURE 4: The 115,169 asthmatic pregnant women were clustered into four distinct groups. Group 1 ( $n=225$, severe persistent group) showed the highest level of daily rank-sum values of asthma medications. Group 2 ( $n=3,251$, improved asthma group) showed an abrupt decreasing trend of rank-sum values during pregnancy and maintained a stable rank-sum value after pregnancy. Group 3 ( $n=2,968$, worsened asthma group) showed an abrupt increasing trend after delivery. Group $4(n=108,725)$ did not show any particular change in trend.

medications for one year before, during, and one year after pregnancy were centered with their global sample mean and were used as explanatory variables. We let $Y_{i}$ be the number of asthma exacerbations of subject $i$. If we denote the centered rank-sum values of the asthma medication before, during, and after pregnancy by $X_{i 1}, X_{i 2}$, and $X_{i 3}$, respectively, the quasi-Poisson regression is

$$
\begin{aligned}
\log E & \left(Y_{i}\right) \\
= & \beta_{0}+\beta_{1} X_{i 1}+\beta_{2} X_{i 2}+\beta_{3} X_{i 3}+\beta_{4} X_{i 1} X_{i 2} \\
& +\beta_{5} X_{i 2} X_{i 3}+\beta_{6} X_{i 1} X_{i 3}
\end{aligned}
$$

$i$ : independent and $\operatorname{var}\left(Y_{i}\right)=c \times E\left(Y_{i}\right)$.

We considered two-way and three-way interactions of ranksum values, and a stepwise selection method was used to find the best model. Estimated regression coefficients and 95\% confidence intervals are presented. All statistical procedures were conducted using the SAS Enterprise statistical software (version 6.1). The alpha level for the determination of significance was 0.10 .

\section{Results}

3.1. Daily Rank-Sum Values of Asthma Medications before, during, and after Pregnancy. The overall rank-sum value of the asthma medications tended to be abruptly reduced just after women became pregnant and slowly increased after pregnancy (Figure 3). Study subjects were clustered into four groups according to the pattern of their asthma medication. Group 1 ( $n=225)$ showed the highest level of daily ranksum values of asthma medications, with many spikes over the study period. Group $2(n=3,251)$ showed the second highest level of rank-sum values before pregnancy and showed an abruptly decreasing trend during pregnancy. Group 3 ( $n=$ 2,968) showed a small decreasing trend during pregnancy compared to before pregnancy and an abruptly increasing trend after delivery. While Group 2 maintained a similar level of rank-sum values during and after pregnancy, Group 3 showed higher rank-sum values after pregnancy than during it. Group $4(n=108,725)$ did not show any particular change in trend (Figure 4). 
TABLE 2: Comparison of oral asthma medications before, during, and after pregnancy.

\begin{tabular}{|c|c|c|c|c|c|}
\hline \multirow{3}{*}{ Medication } & \multirow{3}{*}{ Group } & Before pregnancy & During pregnancy & \multicolumn{2}{|l|}{ After pregnancy } \\
\hline & & \multicolumn{4}{|c|}{ Days/month } \\
\hline & & Mean \pm sd & Mean \pm sd & Mean \pm sd & $P^{*}$ \\
\hline \multirow{5}{*}{ LTRAs } & Total & $0.229 \pm 1.82$ & $0.092 \pm 1.24$ & $0.189 \pm 1.71$ & $<0.0001$ \\
\hline & Group 1 & $3.804 \pm 9.33$ & $3.054 \pm 8.35$ & $4.083 \pm 9.52$ & 0.0003 \\
\hline & Group 2 & $1.946 \pm 6.45$ & $0.852 \pm 4.23$ & $0.97 \pm 4.22$ & $<0.0001$ \\
\hline & Group 3 & $0.925 \pm 4.21$ & $0.568 \pm 3.58$ & $1.477 \pm 5.93$ & $<0.0001$ \\
\hline & Group 4 & $0.151 \pm 1.21$ & $0.05 \pm 0.75$ & $0.122 \pm 1.15$ & $<0.0001$ \\
\hline \multirow{5}{*}{ Xanthine } & Total & $0.05 \pm 0.68$ & $0.017 \pm 0.47$ & $0.028 \pm 0.57$ & $<0.0001$ \\
\hline & Group 1 & $1.684 \pm 6.45$ & $1.592 \pm 6.26$ & $1.43 \pm 5.79$ & 0.3094 \\
\hline & Group 2 & $0.26 \pm 2.07$ & $0.101 \pm 1.32$ & $0.114 \pm 1.14$ & $<0.0001$ \\
\hline & Group 3 & $0.127 \pm 1.2$ & $0.64 \pm 1.11$ & $0.205 \pm 2.05$ & $<0.0001$ \\
\hline & Group 4 & $0.038 \pm 0.48$ & $0.01 \pm 0.25$ & $0.018 \pm 0.34$ & $<0.0001$ \\
\hline \multirow{5}{*}{ LABA } & Total & $0.112 \pm 0.86$ & $0.032 \pm 0.47$ & $0.07 \pm 0.71$ & $<0.0001$ \\
\hline & Group 1 & $0.793 \pm 3.86$ & $0.249 \pm 1.94$ & $0.402 \pm 2.46$ & $<0.0001$ \\
\hline & Group 2 & $0.318 \pm 2.01$ & $0.088 \pm 1.11$ & $0.229 \pm 1.53$ & $<0.0001$ \\
\hline & Group 3 & $0.225 \pm 1.42$ & $0.059 \pm 0.938$ & $0.165 \pm 1.58$ & $<0.0001$ \\
\hline & Group 4 & $0.102 \pm 0.75$ & $0.029 \pm 0.41$ & $0.062 \pm 0.61$ & $<0.0001$ \\
\hline \multirow{5}{*}{ Low-dose systemic corticosteroids } & Total & $0.431 \pm 1.83$ & $0.116 \pm 1.21$ & $0.313 \pm 1.73$ & $<0.0001$ \\
\hline & Group 1 & $14.128 \pm 14.13$ & $13.808 \pm 13.4$ & $15.657 \pm 14.25$ & $<0.0001$ \\
\hline & Group 2 & $2.015 \pm 4.77$ & $0.462 \pm 2.51$ & $1.04 \pm 3.01$ & $<0.0001$ \\
\hline & Group 3 & $1.29 \pm 3.21$ & $0.36 \pm 2.53$ & $1.169 \pm 4.61$ & $<0.0001$ \\
\hline & Group 4 & $0.331 \pm 1.29$ & $0.071 \pm 0.643$ & $0.236 \pm 1.17$ & $<0.0001$ \\
\hline
\end{tabular}

${ }^{*} P$ value according to the multivariate analysis of variance; LTRA, leukotriene receptor antagonist; LABA, long-acting $\beta_{2}$-agonists; sd, standard deviation.

3.2. Patterns of Asthma Medications before, during, and after Pregnancy. The total amounts of asthma medications dispensed are shown in Tables 2 and 3. All of the oral medications including LTRAs, xanthine, LABA, and systemic corticosteroids as a controller dose showed the consistent result that oral asthma medications were less used during pregnancy than before and after pregnancy (Table 2). This finding was consistently observed regardless of group. Otherwise, inhaled asthma medications showed contradictory patterns in that low-to-medium doses of ICSs were used more during pregnancy than before and after it, while other inhaled asthma medications showed similar patterns to the oral ones (Table 3).

3.3. Asthma Exacerbations before, during, and after Pregnancy. Table 4 shows the overall frequencies of variables related to asthma exacerbations. Hospitalization and ED visits were significantly increased during pregnancy $(P<0.001)$; otherwise, overall exacerbations and systemic corticosteroids were decreased $(P<0.001)$ (Figure 5). Asthma-related hospitalizations and ED visits increased in Groups 1 and 3 during pregnancy $(P<0.001)$. However the other groups did not show any change in trend. Group 1 showed similar patterns of overall exacerbations ( $P=0.476)$, systemic corticosteroids $(P=0.173)$, ED visits $(P=0.569)$, and Ventolin nebulizer treatments at the outpatient clinic $(P=0.466)$ during pregnancy, compared to before and after it. Corticosteroid bursts showed a sharp fall at the beginning of pregnancy and slowly increased after delivery (Figure 6). Group 3 shows gradual increases of asthma exacerbations before the pregnancy but there are no asthma exacerbations during the pregnancy. However after the pregnancy, the amount of asthma exacerbations sharply increases and it may be related to poor adherence to asthma medication during pregnancy.

3.4. Outpatient Clinic Utilization before, during, and after Pregnancy. Outpatient clinic utilization according to specialty was calculated as the number of visits to each specialty versus the total number of outpatient visits. Overall outpatient utilization was significantly lower during pregnancy than during the other time periods. As expected, utilization of the obstetrics specialty increased significantly during pregnancy. Meanwhile, utilization of other specialties, in particular internal medicine, showed a significant decrease during pregnancy $(P<0.001)$ (Table 5).

3.5. Associations between the Rank-Sum Values of Asthma Medications and Asthma Exacerbations. Tables 6-9 show the results based on a quasi-Poisson regression in each group. Except for Group 4, the coefficients of $X_{i 1}$ (total use of asthma medications before pregnancy) were significantly negative, which implies that asthma exacerbations during pregnancy tended to be reduced as a greater number of medications were prescribed before pregnancy in Groups 2 and 3. However, 
TABLE 3: Comparison of inhaled asthma medications before, during, and after pregnancy, according to the study groups.

\begin{tabular}{|c|c|c|c|c|c|}
\hline \multirow{3}{*}{ Medication } & \multirow{3}{*}{ Group } & Before pregnancy & During pregnancy & After pregnancy & \\
\hline & & \multicolumn{4}{|c|}{ Doses/month } \\
\hline & & Mean \pm sd & Mean \pm sd & Mean \pm sd & $P^{*}$ \\
\hline \multirow{5}{*}{ Low-dose ICS } & Total & $0.0013 \pm 0.047$ & $0.0031 \pm 0.079$ & $0.0008 \pm 0.038$ & $<0.0001$ \\
\hline & Group 1 & $0.0204 \pm 0.19$ & $0.0631 \pm 0.353$ & $0.0111 \pm 0.156$ & $<0.0001$ \\
\hline & Group 2 & $0.0175 \pm 0.177$ & $0.0434 \pm 0.294$ & $0.0082 \pm 0.123$ & $<0.0001$ \\
\hline & Group 3 & $0.0105 \pm 0.135$ & $0.0277 \pm 0.243$ & $0.0112 \pm 0.149$ & $<0.0001$ \\
\hline & Group 4 & $0.0005 \pm 0.028$ & $0.001 \pm 0.046$ & $0.0003 \pm 0.02$ & $<0.0001$ \\
\hline \multirow{5}{*}{ Medium- to high-dose ICS } & Total & $0.0009 \pm 0.041$ & $0.0029 \pm 0.077$ & $0.0006 \pm 0.035$ & $<0.0001$ \\
\hline & Group 1 & $0.0207 \pm 0.191$ & $0.0636 \pm 0.355$ & $0.011 \pm 0.157$ & $<0.0001$ \\
\hline & Group 2 & $0.0146 \pm 0.169$ & $0.042 \pm 0.291$ & $0.0069 \pm 0.118$ & $<0.0001$ \\
\hline & Group 3 & $0.0086 \pm 0.127$ & $0.0277 \pm 0.243$ & $0.0104 \pm 0.146$ & $<0.0001$ \\
\hline & Group 4 & $0.0002 \pm 0.201$ & $0.001 \pm 0.043$ & $0.0002 \pm 0.017$ & $<0.0001$ \\
\hline \multirow{5}{*}{ Low-dose ICS/LABA } & Total & $0.0057 \pm 0.081$ & $0.0045 \pm 0.073$ & $0.004 \pm 0.069$ & $<0.0001$ \\
\hline & Group 1 & $0.1926 \pm 0.527$ & $0.176 \pm 0.485$ & $0.1715 \pm 0.48$ & 0.2656 \\
\hline & Group 2 & $0.09 \pm 0.315$ & $0.056 \pm 0.25$ & $0.0426 \pm 0.21$ & $<0.0001$ \\
\hline & Group 3 & $0.041 \pm 0.211$ & $0.387 \pm 0.213$ & $0.0588 \pm 0.264$ & $<0.0001$ \\
\hline & Group 4 & $0.0019 \pm 0.044$ & $0.0017 \pm 0.042$ & $0.001 \pm 0.033$ & $<0.0001$ \\
\hline \multirow{5}{*}{$\begin{array}{l}\text { Medium- to high-dose } \\
\text { ICS/LABA }\end{array}$} & Total & $0.0007 \pm 0.036$ & $0.0006 \pm 0.032$ & $0.0005 \pm 0.032$ & 0.0005 \\
\hline & Group 1 & $0.0937 \pm 0.421$ & $0.0769 \pm 0.375$ & $0.0744 \pm 0.367$ & 0.1463 \\
\hline & Group 2 & $0.0127 \pm 0.155$ & $0.0069 \pm 0.114$ & $0.003 \pm 0.071$ & $<0.0001$ \\
\hline & Group 3 & $0.0039 \pm 0.084$ & $0.0057 \pm 0.104$ & $0.0107 \pm 0.143$ & $<0.0001$ \\
\hline & Group 4 & $0.00004 \pm 0.009$ & $0.00006 \pm 0.01$ & $0.00003 \pm 0.008$ & 0.0273 \\
\hline \multirow{5}{*}{ SABAs } & Total & $0.0043 \pm 0.078$ & $0.0034 \pm 0.067$ & $0.0032 \pm 0.037$ & $<0.0001$ \\
\hline & Group 1 & $0.1059 \pm 0.375$ & $0.1053 \pm 0.395$ & $0.1081 \pm 0.431$ & 0.9656 \\
\hline & Group 2 & $0.0352 \pm 0.21$ & $0.0304 \pm 0.196$ & $0.0281 \pm 0.192$ & $<0.0001$ \\
\hline & Group 3 & $0.0192 \pm 0.154$ & $0.0192 \pm 0.164$ & $0.0202 \pm 0.171$ & 0.6736 \\
\hline & Group 4 & $0.0027 \pm 0.064$ & $0.002 \pm 0.05$ & $0.0018 \pm 0.05$ & $<0.0001$ \\
\hline \multirow{5}{*}{ LAMA } & Total & $0.00004 \pm 0.002$ & $0.00001 \pm 0.002$ & $0.00002 \pm 0.005$ & $<0.0001$ \\
\hline & Group 1 & $0.00037 \pm 0.019$ & $0.0013 \pm 0.036$ & $0.0056 \pm 0.079$ & 0.0006 \\
\hline & Group 2 & $0.00005 \pm 0.007$ & 0 & $0.00026 \pm 0.005$ & 0.4227 \\
\hline & Group 3 & $0.00003 \pm 0.005$ & $0.0001 \pm 0.01$ & $0.00036 \pm 0.019$ & 0.0014 \\
\hline & Group 4 & $0.00001 \pm 0.001$ & 0 & $0.00002 \pm 0.001$ & 0.4227 \\
\hline
\end{tabular}

${ }^{*} P$ value according to the multivariate analysis of variance; ICS, inhaled corticosteroid; LABA, long-acting $\beta_{2}$-agonists; SABAs, short-acting $\beta_{2}$-agonists; LAMA, long-acting muscarinic antagonists; sd, standard deviation.

in Group 4, the coefficients of $X_{i 1}$ in systemic corticosteroid prescriptions, ED visits, and overall exacerbations were positive. Moreover, there was no significant association in Group 1 between asthma exacerbations and the total usage of medication over time. In all groups except Group 1 , the coefficients of $X_{i 2}$ (total use of asthma medications during pregnancy) were significantly positive, indicating that subjects with a higher level of medication during pregnancy tended to have more asthma exacerbations. In Groups 3 and 4, there were positive associations between $X_{i 3}$ (total use of asthma medications after pregnancy) and asthma exacerbations. Finally, the proportions of subjects with asthma exacerbations during pregnancy could be explained by the level of asthma medications during the time periods before and during pregnancy (Table 10).

3.6. Annual Prevalence of Asthma during Pregnancy. The annual prevalence of asthma during pregnancy was $4.48 \%$ (95\% CI, $4.42 \%-4.54 \%)$ in $2011,4.61 \%$ (95\% CI, $4.55 \%-4.67 \%$ ) in 2012 , and $4.97 \%$ (95\% CI, $4.91 \%-5.04 \%$ ) in 
TABLE 4: Comparison of asthma exacerbations before, during, and after pregnancy, according to the study groups.

\begin{tabular}{|c|c|c|c|c|c|}
\hline \multirow{3}{*}{ Exacerbation } & \multirow{3}{*}{ Group } & Before pregnancy & During pregnancy & After pregnancy & \multirow[b]{3}{*}{$P^{*}$} \\
\hline & & & Frequencies/month & & \\
\hline & & Mean \pm sd & Mean \pm sd & Mean \pm sd & \\
\hline \multirow{5}{*}{$\begin{array}{l}\text { Systemic corticosteroid } \\
\text { prescription }\end{array}$} & Total & $0.0081 \pm 0.116$ & $0.0027 \pm 0.059$ & $0.0054 \pm 0.096$ & $<0.0001$ \\
\hline & Group 1 & $0.0307 \pm 0.195$ & $0.0293 \pm 0.211$ & $0.04 \pm 0.273$ & 0.1703 \\
\hline & Group 2 & $0.0205 \pm 0.213$ & $0.0073 \pm 0.097$ & $0.0142 \pm 0.156$ & $<0.0001$ \\
\hline & Group 3 & $0.0222 \pm 0.22$ & $0.0057 \pm 0.088$ & $0.0117 \pm 0.169$ & $<0.0001$ \\
\hline & Group 4 & $0.0072 \pm 0.107$ & $0.0025 \pm 0.056$ & $0.0048 \pm 0.09$ & $<0.0001$ \\
\hline \multirow{5}{*}{ Hospitalization } & Total & $0.0005 \pm 0.023$ & $0.0007 \pm 0.028$ & $0.0002 \pm 0.015$ & $<0.0001$ \\
\hline & Group 1 & $0.0074 \pm 0.094$ & $0.0164 \pm 0.137$ & $0.007 \pm 0.084$ & 0.0023 \\
\hline & Group 2 & $0.003 \pm 0.056$ & $0.0052 \pm 0.076$ & $0.0012 \pm 0.034$ & $<0.0001$ \\
\hline & Group 3 & $0.0012 \pm 0.035$ & $0.0045 \pm 0.073$ & $0.0015 \pm 0.041$ & $<0.0001$ \\
\hline & Group 4 & $0.0004 \pm 0.021$ & $0.0004 \pm 0.021$ & $0.0001 \pm 0.012$ & $<0.0001$ \\
\hline \multirow{5}{*}{ ED visit } & Total & $0.0001 \pm 0.01$ & $0.0002 \pm 0.016$ & $0.00004 \pm 0.007$ & $<0.0001$ \\
\hline & Group 1 & $0.0033 \pm 0.064$ & $0.0049 \pm 0.082$ & $0.003 \pm 0.054$ & 0.5691 \\
\hline & Group 2 & $0.0009 \pm 0.031$ & $0.0022 \pm 0.05$ & $0.0003 \pm 0.018$ & $<0.0001$ \\
\hline & Group 3 & $0.0003 \pm 0.016$ & $0.0018 \pm 0.044$ & $0.0006 \pm 0.025$ & $<0.0001$ \\
\hline & Group 4 & $0.0001 \pm 0.008$ & $0.0001 \pm 0.011$ & $0.00002 \pm 0.004$ & $<0.0001$ \\
\hline \multirow{5}{*}{ Overall exacerbation } & Total & $0.0087 \pm 0.121$ & $0.0037 \pm 0.075$ & $0.0056 \pm 0.099$ & $<0.0001$ \\
\hline & Group 1 & $0.0415 \pm 0.272$ & $0.0507 \pm 0.335$ & $0.0504 \pm 0.323$ & 0.4758 \\
\hline & Group 2 & $0.0289 \pm 0.235$ & $0.0146 \pm 0.167$ & $0.0157 \pm 0.165$ & $<0.0001$ \\
\hline & Group 3 & $0.0236 \pm 0.228$ & $0.0119 \pm 0.161$ & $0.0138 \pm 0.184$ & $<0.0001$ \\
\hline & Group 4 & $0.0077 \pm 0.111$ & $0.003 \pm 0.065$ & $0.005 \pm 0.092$ & $<0.0001$ \\
\hline \multirow{5}{*}{$\begin{array}{l}\text { Ventolin nebulizer } \\
\text { treatment }\end{array}$} & Total & $0.0032 \pm 0.061$ & $0.003 \pm 0.059$ & $0.0026 \pm 0.057$ & $<0.0001$ \\
\hline & Group 1 & $0.0967 \pm 0.347$ & $0.0844 \pm 0.328$ & $0.0904 \pm 0.363$ & 0.4664 \\
\hline & Group 2 & $0.0333 \pm 0.199$ & $0.0293 \pm 0.189$ & $0.0259 \pm 0.177$ & $<0.0001$ \\
\hline & Group 3 & $0.0175 \pm 0.144$ & $0.0181 \pm 0.157$ & $0.0187 \pm 0.159$ & 0.5906 \\
\hline & Group 4 & $0.0018 \pm 0.044$ & $0.0016 \pm 0.041$ & $0.0012 \pm 0.038$ & $<0.0001$ \\
\hline
\end{tabular}

${ }^{*} P$ value according to the multivariate analysis of variance; ED, emergency department; sd, standard deviation.

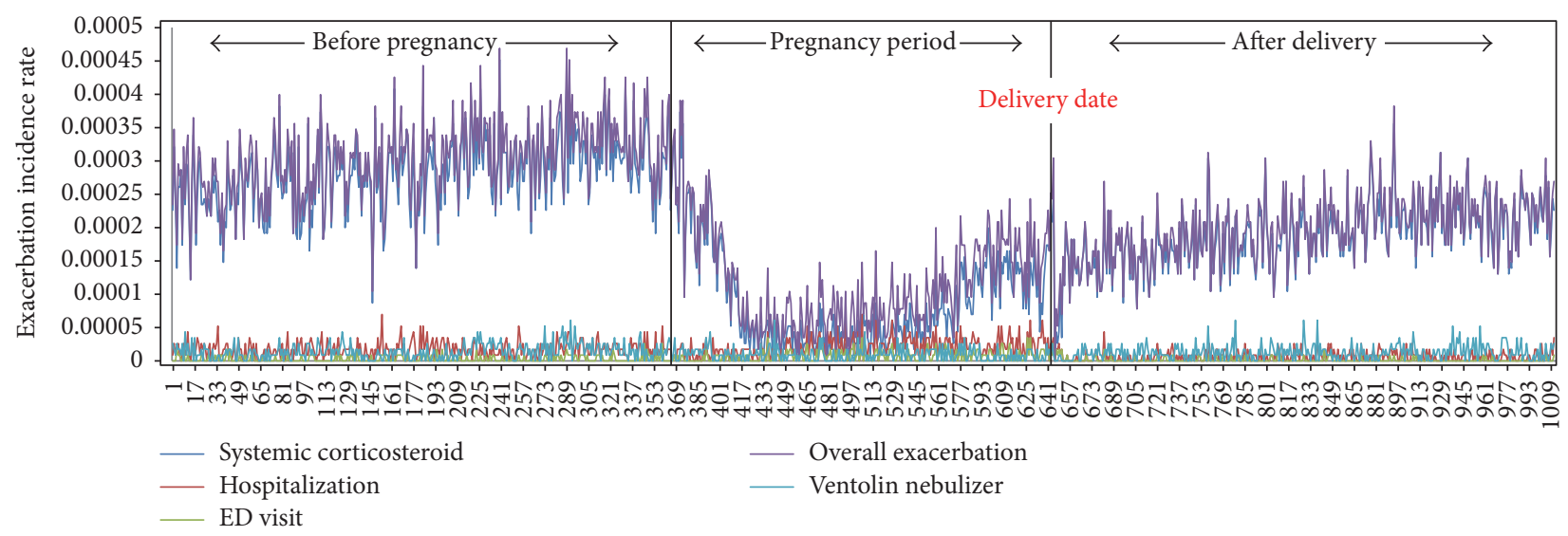

FIgURE 5: The overall asthma exacerbations were observed less during pregnancy than before and after it. Corticosteroid burst therapy showed a sharp fall at the beginning of pregnancy and slowly increased after delivery. None of the asthma-related hospitalizations, emergency department (ED) visits, and Ventolin nebulizer treatments at the outpatient clinic showed an increasing trend during pregnancy. 


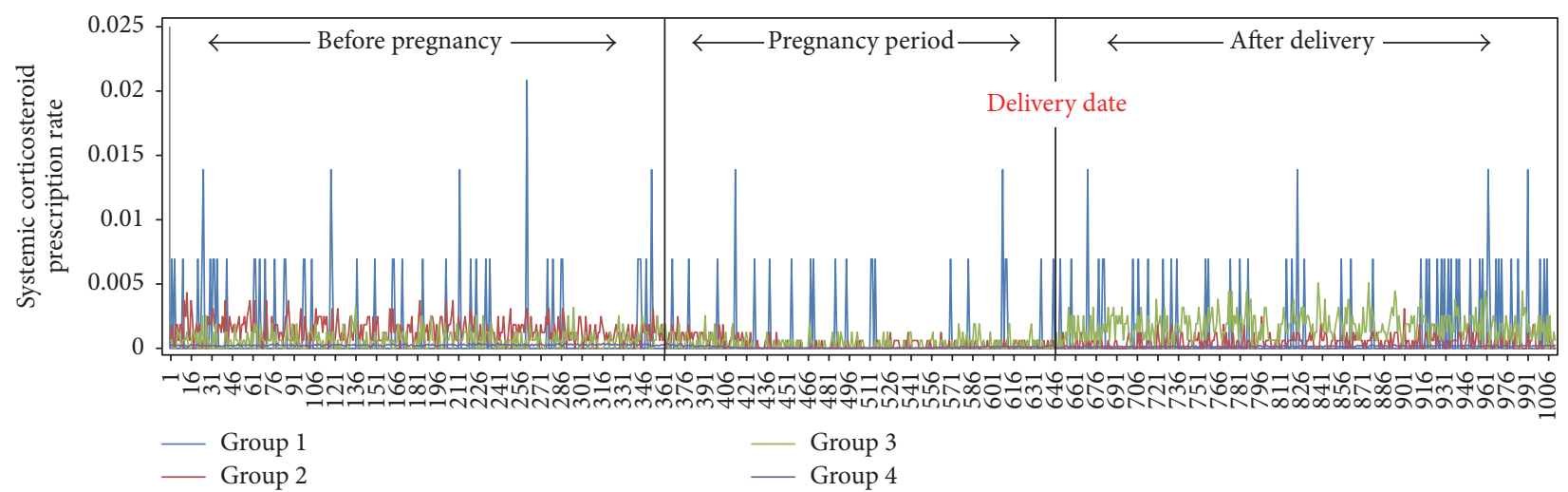

FIGURE 6: Use of systemic corticosteroids according to the study groups. Corticosteroid burst therapy showed a sharp fall at the beginning of pregnancy and slowly increased after delivery across the 4 groups.

2013. No significant trend was observed through the years $(p=0.30)$.

\section{Discussion}

We have presented quantitative rank-sum values of asthma medications and their correlation with asthma exacerbations during pregnancy and compared the effect of pregnancy on the maintenance of asthma medications and asthma exacerbation during pregnancy to that before and after pregnancy. This study was conducted as a nationwide populationbased retrospective cohort study using the HIRA database and included 115,169 asthmatic pregnant women. Our study showed that qualitative and quantitative asthma medications were reduced in most asthmatics during pregnancy.

It is well known that approximately one-third of asthma patients naturally improve during pregnancy. Similarly, in our study, we found that some of the asthmatic pregnant women did improve. Conversely, some of the patients experienced a worsened level of control during pregnancy. Among 115,169 asthmatic pregnant women, all subjects were clustered into four groups: severe persistent ( $n=225,0.19 \%$ ), mild persistent $(n=108,725,94.4 \%)$, worsened $(n=2,968,2.58 \%)$, and improved ( $n=3,251,2.82 \%)$ asthma during pregnancy. The patterns of asthma medication use and their correlation with asthma exacerbation differed according to the study groups. Interestingly among our clustered groups, subjects in Group 3 tend to avoid asthma medication during pregnancy. However, there was no overall correlation between reduced asthma medications and asthma exacerbations during pregnancy in each group.

We hypothesized that a reduction of asthma medication during pregnancy might be correlated with asthma exacerbations. However, our findings showed the opposite, where a higher level of asthma medication use tended to produce more asthma exacerbations in each group. The results suggested that asthma exacerbations depend more on the baseline severity of asthma and its natural course during pregnancy than on adherence to asthma medication use if group effects are controlled. Therefore, it is clinically significant that individualized therapeutic strategies are utilized, including closed monitoring, and the active control of susceptible pregnant asthma patients before and during pregnancy is warranted.

Many studies have demonstrated that pregnant women preferred to use ICS monotherapy rather than oral or combination asthma medications due to concerns regarding systemic adverse effects [11, 12]. A recent study in seven European regions reported that the overall prescription of oral asthma medications, such as oral prednisolone and LTRAs, was reduced during pregnancy and an interpretation of their results suggested that LTRAs should not be started during pregnancy but could continue in women who were already using them for the successful control of their asthma before pregnancy [12]. Systemic corticosteroids and highdose ICS are known to increase the risk of preeclampsia, low birth weight, and preterm delivery $[33,34]$. Although several studies and guidelines have emphasized that an adequate dose of ICS and SABA did not affect pregnancy outcomes $[6,35]$, pregnant women have been reluctant to take steroids during pregnancy due to safety concerns. Our findings also support previous results that South Korean asthmatic pregnant women preferred ICS-based inhalers over oral asthma medications regardless of the severity of their asthma and the level of asthma medications before pregnancy [7]. In reality, the US and Korean Food and Drug Administration put most asthma medications, even inhalers, into category C. Achieving well-controlled asthma will greatly reduce the need for high-dose ICSs or systemic corticosteroids and also prevent the risk of adverse pregnancy or perinatal outcomes [33].

The strengths of the current study are as follows: this study was a nationwide cohort study with a large sample size. The HIRA data used in the current study included all information with respect to hospital stays as well as ED visits and outpatient utilization. Previous studies conducted in Europe have noted that a lack of information on hospital stays was an inherent limitation of their studies [11, 12]. Indeed, information on hospital stays would be extremely valuable in exploring the reduction of asthma medications and their 
TABLE 5: Comparison of outpatient clinic visits before, during, and after pregnancy, according to the study groups.

\begin{tabular}{|c|c|c|c|c|c|}
\hline \multirow{3}{*}{ Exacerbation } & \multirow{3}{*}{ Group } & Before pregnancy & During pregnancy & After pregnancy & \\
\hline & & \multicolumn{4}{|c|}{ Visits/month } \\
\hline & & Mean \pm sd & Mean \pm sd & Mean \pm sd & $P^{*}$ \\
\hline \multirow{5}{*}{$\begin{array}{l}\text { Total number of outpatient } \\
\text { visits }\end{array}$} & Total & $1.1267 \pm 2.467$ & $1.9067 \pm 2.411$ & $1.1998 \pm 2.876$ & $<0.0001$ \\
\hline & Group 1 & $2.2038 \pm 6.667$ & $2.9278 \pm 6.313$ & $2.2594 \pm 6.344$ & 0.8767 \\
\hline & Group 2 & $1.9313 \pm 4.51$ & $2.3157 \pm 4.86$ & $1.8011 \pm 4.387$ & 0.2158 \\
\hline & Group 3 & $1.6899 \pm 3.89$ & $2.091 \pm 4.54$ & $1.3879 \pm 4.19$ & 0.3454 \\
\hline & Group 4 & $1.1287 \pm 2.471$ & $1.8867 \pm 2.388$ & $1.1576 \pm 2.612$ & 0.1345 \\
\hline \multirow{5}{*}{ Internal medicine } & Total & $0.4312 \pm 1.934$ & $0.2178 \pm 1.813$ & $0.4062 \pm 1.864$ & $<0.0001$ \\
\hline & Group 1 & $1.0946 \pm 5.412$ & $1.0156 \pm 5.167$ & $1.1599 \pm 5.678$ & 0.3154 \\
\hline & Group 2 & $0.8176 \pm 2.972$ & $0.4467 \pm 2.34$ & $0.6678 \pm 2.871$ & $<0.0001$ \\
\hline & Group 3 & $0.6479 \pm 2.72$ & $0.3196 \pm 2.14$ & $0.5137 \pm 2.64$ & $<0.0001$ \\
\hline & Group 4 & $0.4579 \pm 1.595$ & $0.2189 \pm 1.648$ & $0.3846 \pm 1.754$ & $<0.0001$ \\
\hline \multirow{5}{*}{ Obstetrics and gynecology } & Total & $0.2167 \pm 1.534$ & $1.4376 \pm 3.034$ & $0.2676 \pm 1.76$ & $<0.0001$ \\
\hline & Group 1 & $0.3066 \pm 2.879$ & $1.4567 \pm 5.166$ & $0.2675 \pm 2.433$ & $<0.0001$ \\
\hline & Group 2 & $0.2345 \pm 1.872$ & $1.4699 \pm 3.84$ & $0.2788 \pm 2.103$ & $<0.0001$ \\
\hline & Group 3 & $0.2387 \pm 1.878$ & $1.4678 \pm 3.416$ & $0.2647 \pm 2.037$ & $<0.0001$ \\
\hline & Group 4 & $0.2134 \pm 1.16$ & $1.4122 \pm 2.768$ & $0.2478 \pm 1.652$ & $<0.0001$ \\
\hline \multirow{5}{*}{ General practitioner } & Total & $0.0016 \pm 0.049$ & $0.0012 \pm 0.027$ & $0.0019 \pm 0.051$ & $<0.0001$ \\
\hline & Group 1 & $0.0213 \pm 0.541$ & $0.0027 \pm 0.161$ & $0.0008 \pm 0.071$ & 0.2134 \\
\hline & Group 2 & $0.0027 \pm 0.073$ & $0.0014 \pm 0.054$ & $0.0026 \pm 0.067$ & 0.0154 \\
\hline & Group 3 & $0.0024 \pm 0.068$ & $0.0019 \pm 0.061$ & $0.0022 \pm 0.063$ & $<0.0001$ \\
\hline & Group 4 & $0.0017 \pm 0.042$ & $0.0015 \pm 0.038$ & $0.0019 \pm 0.04$ & $<0.0001$ \\
\hline \multirow{5}{*}{ General surgery } & Total & $0.0307 \pm 0.713$ & $0.0208 \pm 0.498$ & $0.0312 \pm 0.671$ & $<0.0001$ \\
\hline & Group 1 & $0.05 \pm 0.78$ & $0.017 \pm 0.064$ & $0.0421 \pm 0.59$ & 0.2783 \\
\hline & Group 2 & $0.0374 \pm 0.201$ & $0.0233 \pm 0.068$ & $0.0419 \pm 0.204$ & $<0.0001$ \\
\hline & Group 3 & $0.0337 \pm 0.179$ & $0.0217 \pm 0.22$ & $0.0347 \pm 0.483$ & $<0.0001$ \\
\hline & Group 4 & $0.0307 \pm 0.462$ & $0.0201 \pm 0.216$ & $0.0318 \pm 0.475$ & $<0.0001$ \\
\hline \multirow{5}{*}{ Otolaryngology } & Total & $0.1678 \pm 1.57$ & $0.0617 \pm 0.514$ & $0.1248 \pm 0.876$ & $<0.0001$ \\
\hline & Group 1 & $0.2097 \pm 2.376$ & $0.137 \pm 1.164$ & $0.1724 \pm 1.311$ & 0.1674 \\
\hline & Group 2 & $0.2648 \pm 2.186$ & $0.1301 \pm 1.152$ & $0.1924 \pm 0.954$ & $<0.0001$ \\
\hline & Group 3 & $0.2467 \pm 2.067$ & $0.0846 \pm 0.867$ & $0.1154 \pm 0.941$ & $<0.0001$ \\
\hline & Group 4 & $0.1597 \pm 2.276$ & $0.0678 \pm 0.531$ & $0.1038 \pm 0.775$ & $<0.0001$ \\
\hline \multirow{5}{*}{ Family medicine } & Total & $0.0237 \pm 0.872$ & $0.0084 \pm 0.103$ & $0.0211 \pm 0.612$ & $<0.0001$ \\
\hline & Group 1 & 0 & $0.017 \pm 0.51$ & $0.0005 \pm 0.003$ & $<0.0001$ \\
\hline & Group 2 & $0.0357 \pm 0.193$ & $0.013 \pm 0.167$ & $0.0007 \pm 0.008$ & $<0.0001$ \\
\hline & Group 3 & $0.0287 \pm 0.178$ & $0.0107 \pm 0.158$ & $0.0004 \pm 0.005$ & $<0.0001$ \\
\hline & Group 4 & $0.0248 \pm 0.387$ & $0.0072 \pm 0.113$ & $0.0218 \pm 0.412$ & $<0.0001$ \\
\hline
\end{tabular}

${ }^{*} P$ value according to the multivariate analysis of variance.

association with asthma symptoms. Moreover, quantitative analysis using the rank-sum values of asthma medications and clustering of groups according to the rank-sum values of asthma medications would be a valuable approach. All of the previous studies have analyzed a rate or frequency of asthma medication at the group level $[7,11,12,14]$. However, we considered the daily rank-sum values of asthma medications at the individual level and categorized all subjects into four groups, namely, severe persistent, mild persistent, worsened, and improved asthma during pregnancy. We found that the 
TABLE 6: General linear mixed models to estimate asthma medication pattern variables over the study period to predict asthma exacerbation in Group 1.

\begin{tabular}{|c|c|c|c|c|c|c|c|c|}
\hline \multirow{2}{*}{ Outcome variable } & \multirow{2}{*}{ Explanatory variable } & \multirow{2}{*}{ Estimate } & \multirow{2}{*}{ Standard Error } & \multirow{2}{*}{$\mathrm{DF}$} & \multirow{2}{*}{$t$-value } & \multirow{2}{*}{$P$ value } & \multicolumn{2}{|c|}{$95 \% \mathrm{CI}$} \\
\hline & & & & & & & Lower & Upper \\
\hline \multirow{3}{*}{$\begin{array}{l}\text { Systemic corticosteroid } \\
\text { prescription }\end{array}$} & Intercept & -0.9301 & 0.2563 & 222 & -3.63 & 0.0004 & -1.4324 & -0.4278 \\
\hline & $X_{i 1}$ & -0.00036 & 0.000563 & 222 & -0.64 & 0.5242 & -0.0015 & 0.00074 \\
\hline & $X_{i 2}$ & -0.00036 & 0.000698 & 222 & -0.51 & 0.6072 & -0.0017 & 0.00101 \\
\hline \multirow{3}{*}{ Hospitalization } & Intercept & -1.9751 & 0.2567 & 222 & -7.69 & $<0.0001$ & -2.4782 & -1.472 \\
\hline & $X_{i 1}$ & -0.00075 & 0.000542 & 222 & -1.38 & 0.1683 & -0.0018 & 0.00031 \\
\hline & $X_{i 2}$ & 0.0001 & 0.00071 & 222 & 0.14 & 0.8878 & -0.0013 & 0.00149 \\
\hline \multirow{3}{*}{ ED visit } & Intercept & -3.2084 & 0.4634 & 222 & -6.92 & $<0.0001$ & -4.1167 & -2.3001 \\
\hline & $X_{i 1}$ & -0.00078 & 0.000929 & 222 & -0.84 & 0.403 & -0.0026 & 0.00104 \\
\hline & $X_{i 2}$ & 0.000964 & 0.001373 & 222 & 0.7 & 0.4832 & -0.0017 & 0.00366 \\
\hline \multirow{3}{*}{ Overall exacerbation } & Intercept & -0.5459 & 0.2238 & 222 & -2.44 & 0.0155 & -0.9845 & -0.1073 \\
\hline & $X_{i 1}$ & -0.00049 & 0.000488 & 222 & -1 & 0.3197 & -0.0014 & 0.00047 \\
\hline & $X_{i 2}$ & -0.00016 & 0.000618 & 222 & -0.26 & 0.7956 & -0.0014 & 0.00105 \\
\hline \multirow{3}{*}{$\begin{array}{l}\text { Ventolin nebulizer } \\
\text { treatment }\end{array}$} & Intercept & -1.9872 & 0.5328 & 222 & -3.73 & 0.0002 & -3.0315 & -0.9429 \\
\hline & $X_{i 1}$ & -0.00073 & 0.001117 & 222 & -0.66 & 0.5126 & -0.0029 & 0.00146 \\
\hline & $X_{i 2}$ & -0.00032 & 0.0014 & 222 & -0.23 & 0.8167 & -0.0031 & 0.00242 \\
\hline
\end{tabular}

$X_{i 1}$, total use of asthma medications before pregnancy; $X_{i 2}$, total use of asthma medications during pregnancy; ED, emergency department; DF, degree of freedom; CI, confidence interval.

TABLE 7: General linear mixed models to estimate asthma medication pattern variables over the study period to predict asthma exacerbation in Group 2.

\begin{tabular}{|c|c|c|c|c|c|c|c|c|}
\hline \multirow{2}{*}{ Outcome variable } & \multirow{2}{*}{ Explanatory variable } & \multirow{2}{*}{ Estimate } & \multirow{2}{*}{ Standard Error } & \multirow{2}{*}{$\mathrm{DF}$} & \multirow{2}{*}{$t$-value } & \multirow{2}{*}{$P$ value } & \multicolumn{2}{|c|}{$95 \% \mathrm{CI}$} \\
\hline & & & & & & & Lower & Upper \\
\hline \multirow{3}{*}{$\begin{array}{l}\text { Systemic corticosteroid } \\
\text { prescription }\end{array}$} & Intercept & -2.801 & 0.09869 & 3248 & -28.38 & $<0.0001$ & -2.9944 & -2.6076 \\
\hline & $X_{i 1}$ & -0.00172 & 0.000575 & 3248 & -2.98 & 0.0029 & -0.0028 & -0.0006 \\
\hline & $X_{i 2}$ & 0.002588 & 0.000576 & 3248 & 4.5 & $<0.0001$ & 0.00146 & 0.00372 \\
\hline \multirow{3}{*}{ Hospitalization } & Intercept & -3.5395 & 0.1251 & 3248 & -28.28 & $<0.0001$ & -3.7847 & -3.2943 \\
\hline & $X_{i 1}$ & -0.00332 & 0.00068 & 3248 & -4.88 & $<0.0001$ & -0.0047 & -0.002 \\
\hline & $X_{i 2}$ & 0.004318 & 0.000505 & 3248 & 8.55 & $<0.0001$ & 0.00333 & 0.00531 \\
\hline \multirow{5}{*}{ ED visit } & Intercept & -4.193 & 0.1568 & 3246 & -26.75 & $<0.0001$ & -4.5003 & -3.8857 \\
\hline & $X_{i 1}$ & -0.00156 & 0.000976 & 3246 & -1.6 & 0.1093 & -0.0035 & 0.00035 \\
\hline & $X_{i 2}$ & 0.004638 & 0.000645 & 3246 & 7.2 & $<0.0001$ & 0.00337 & 0.0059 \\
\hline & $X_{i 3}$ & 0.002408 & 0.001377 & 3246 & 1.75 & 0.0805 & -0.0003 & 0.00511 \\
\hline & $X_{i 1} * X_{i 2}$ & -0.000006 & 0.000003 & 3246 & -1.87 & 0.061 & -0.00001 & 0.0000003 \\
\hline \multirow{3}{*}{ Overall exacerbation } & Intercept & -2.2493 & 0.08595 & 3248 & -26.17 & $<0.0001$ & -2.4178 & -2.0808 \\
\hline & $X_{i 1}$ & -0.00232 & 0.000482 & 3248 & -4.82 & $<0.0001$ & -0.0033 & -0.0014 \\
\hline & $X_{i 2}$ & 0.003557 & 0.000412 & 3248 & 8.63 & $<0.0001$ & 0.00275 & 0.00436 \\
\hline \multirow{3}{*}{$\begin{array}{l}\text { Ventolin nebulizer } \\
\text { treatment }\end{array}$} & Intercept & -5.5041 & 0.4281 & 3248 & -12.86 & $<0.0001$ & -6.3432 & -4.665 \\
\hline & $X_{i 1}$ & -0.00157 & 0.002348 & 3248 & -0.67 & 0.5043 & -0.0062 & 0.00303 \\
\hline & $X_{i 2}$ & 0.003411 & 0.002116 & 3248 & 1.61 & 0.1071 & -0.0007 & 0.00756 \\
\hline
\end{tabular}

$X_{i 1}$, total use of asthma medications before pregnancy; $X_{i 2}$, total use of asthma medications during pregnancy; $X_{i 3}$, total use of asthma medications after delivery; $\mathrm{ED}$, emergency department; $\mathrm{DF}$, degree of freedom; CI, confidence interval. 
TABLE 8: General linear mixed models to estimate medication pattern variables over the study period to predict asthma exacerbation in Group 3.

\begin{tabular}{|c|c|c|c|c|c|c|c|c|}
\hline \multirow{2}{*}{ Outcome variable } & \multirow{2}{*}{ Explanatory variable } & \multirow{2}{*}{ Estimate } & \multirow{2}{*}{ Standard Error } & \multirow{2}{*}{$\mathrm{DF}$} & \multirow{2}{*}{$t$-value } & \multirow{2}{*}{$P$ value } & \multicolumn{2}{|c|}{$95 \% \mathrm{CI}$} \\
\hline & & & & & & & Lower & Upper \\
\hline \multirow{5}{*}{$\begin{array}{l}\text { Systemic corticosteroid } \\
\text { prescription }\end{array}$} & Intercept & -3.1987 & 0.1148 & 2963 & -27.86 & $<0.0001$ & -3.4237 & -2.9737 \\
\hline & $X_{i 1}$ & -0.00086 & 0.000719 & 2963 & -1.2 & 0.2298 & -0.0023 & 0.00055 \\
\hline & $X_{i 2}$ & 0.003845 & 0.000404 & 2963 & 9.53 & $<0.0001$ & 0.00305 & 0.00464 \\
\hline & $X_{i 3}$ & 0.001945 & 0.000288 & 2963 & 6.76 & $<0.0001$ & 0.00138 & 0.00251 \\
\hline & $X_{i 2} * X_{i 3}$ & -0.000004 & 0.000001 & 2963 & -3.03 & 0.0024 & -0.000006 & -0.000001 \\
\hline \multirow{3}{*}{ Hospitalization } & Intercept & -3.5983 & 0.1196 & 2965 & -30.1 & $<0.0001$ & -3.8327 & -3.3639 \\
\hline & $X_{i 1}$ & -0.00112 & 0.00084 & 2965 & -1.33 & 0.1825 & -0.0028 & 0.00053 \\
\hline & $X_{i 2}$ & 0.004252 & 0.000341 & 2965 & 12.48 & $<0.0001$ & 0.00358 & 0.00492 \\
\hline \multirow{6}{*}{ ED visit } & Intercept & -4.8786 & 0.1756 & 2962 & -27.78 & $<0.0001$ & -5.2228 & -4.5344 \\
\hline & $X_{i 1}$ & -0.00666 & 0.001862 & 2962 & -3.58 & 0.0004 & -0.0103 & -0.003 \\
\hline & $X_{i 2}$ & 0.004306 & 0.000485 & 2962 & 8.88 & $<0.0001$ & 0.00336 & 0.00526 \\
\hline & $X_{i 3}$ & 0.003262 & 0.0003 & 2962 & 10.89 & $<0.0001$ & 0.00267 & 0.00385 \\
\hline & $X_{i 2} * X_{i 3}$ & -0.000005 & 0.000001 & 2962 & -3.8 & 0.0001 & -0.000007 & -0.000002 \\
\hline & $X_{i 1} * X_{i 3}$ & 0.000009 & 0.000003 & 2962 & 3.27 & 0.0011 & 0.000004 & 0.000015 \\
\hline \multirow{5}{*}{ Overall exacerbation } & Intercept & -2.6632 & 0.09936 & 2963 & -26.8 & $<0.0001$ & -2.8579 & -2.4685 \\
\hline & $X_{i 1}$ & -0.00364 & 0.001236 & 2963 & -2.95 & 0.0033 & -0.0061 & -0.0012 \\
\hline & $X_{i 2}$ & 0.003166 & 0.000308 & 2963 & 10.28 & $<0.0001$ & 0.00256 & 0.00377 \\
\hline & $X_{i 3}$ & 0.001941 & 0.000214 & 2963 & 9.06 & $<0.0001$ & 0.00152 & 0.00236 \\
\hline & $X_{i 1} * X_{i 3}$ & 0.000004 & 0.000002 & 2963 & 1.94 & 0.0524 & -0.00000004 & 0.000009 \\
\hline \multirow{3}{*}{$\begin{array}{l}\text { Ventolin nebulizer } \\
\text { treatment }\end{array}$} & Intercept & -5.8844 & 0.383 & 2965 & -15.36 & $<0.0001$ & -6.6351 & -5.1337 \\
\hline & $X_{i 1}$ & -0.00104 & 0.003013 & 2965 & -0.35 & 0.7287 & -0.0069 & 0.00487 \\
\hline & $X_{i 2}$ & 0.003631 & 0.001277 & 2965 & 2.84 & 0.0045 & 0.00113 & 0.00613 \\
\hline
\end{tabular}

$X_{i 1}$, total use of asthma medications before pregnancy; $X_{i 2}$, total use of asthma medications during pregnancy; $X_{i 3}$, total use of asthma medications after delivery; $\mathrm{ED}$, emergency department; $\mathrm{DF}$, degree of freedom; $\mathrm{CI}$, confidence interval.

patterns of asthma medication use and their correlation with asthma exacerbations differed according to the study groups. Furthermore, subjects in Group 3 tend to avoid asthma medication during pregnancy.

Our study had several limitations. First, while we were able to find accurate records regarding the prescription and dispensing of asthma medications, this did not guarantee that patients actually used the drugs. In reality, this is an inherent limitation of healthcare database analysis. To overcome this limitation, a well-designed prospective cohort study should be considered. Second, the HIRA data did not contain objective measurements including lung function tests or bronchial provocation tests reflecting a confirmed asthma diagnosis and asthma severity. It also did not include subjective measurements such as the asthma control test to reflect asthma symptoms. For these reasons, the HIRA data did not guarantee an accurate diagnosis of asthma and determination of asthma exacerbations. The prevalence of asthma during pregnancy was approximately $8.7 \%$ in our study, which is consistent with the previous findings. Taking these findings together, we hypothesized that asthmatic pregnant women tended to discontinue asthma medication and that this factor was related to increased asthma exacerbations. Oral asthma medications and combination inhalers rather than inhaler corticosteroids were stopped from the beginning through to the end of pregnancy. Increased asthma exacerbations were found only in a small part of the cohort despite an overall reduction in the use of asthma medications. Owing to the limitation of the HIRA data, we failed to conclude whether reduced asthma exacerbations were derived from an improvement of asthma, avoidance of healthcare utilization, or ignoring symptoms due to concerns regarding medicationrelated adverse effects on their fetus.

In conclusion, asthmatic pregnant women showed a trend for stopping asthma medication early on in pregnancy and showed more asthma exacerbations in the subpopulations. These results have an important implication in the management of asthmatic pregnant women. Further research on the safety of asthma medication during pregnancy and guidelinebased education emphasizing the importance of maintenance therapy during pregnancy will be essential. 
TABLE 9: General linear mixed models to estimate medication pattern variables over the study period to predict asthma exacerbation in Group 4 .

\begin{tabular}{|c|c|c|c|c|c|c|c|c|}
\hline \multirow{2}{*}{ Outcome variable } & \multirow{2}{*}{ Explanatory variable } & \multirow{2}{*}{ Estimate } & \multirow{2}{*}{ Standard Error } & \multirow{2}{*}{$\mathrm{DF}$} & \multirow{2}{*}{$t$-value } & \multirow{2}{*}{$P$ value } & \multicolumn{2}{|c|}{$95 \% \mathrm{CI}$} \\
\hline & & & & & & & Lower & Upper \\
\hline \multirow{6}{*}{$\begin{array}{l}\text { Systemic corticosteroid } \\
\text { prescription }\end{array}$} & Intercept & -3.8531 & 0.02787 & 109000 & -138.25 & $<0.0001$ & -3.9077 & -3.7985 \\
\hline & $X_{i 1}$ & 0.002234 & 0.000959 & 109000 & 2.33 & 0.0198 & 0.00035 & 0.00411 \\
\hline & $X_{i 2}$ & 0.01219 & 0.000543 & 109000 & 22.46 & $<0.0001$ & 0.01113 & 0.01325 \\
\hline & $X_{i 3}$ & 0.00531 & 0.000797 & 109000 & 6.66 & $<0.0001$ & 0.00375 & 0.00687 \\
\hline & $X_{i 2} * X_{i 3}$ & -0.00004 & 0.000011 & 109000 & -3.24 & 0.0012 & -0.00006 & -0.00002 \\
\hline & $X_{i 1} * X_{i 3}$ & -0.00004 & 0.000022 & 109000 & -1.94 & 0.0518 & -0.00008 & 0.000003 \\
\hline \multirow{7}{*}{ Hospitalization } & Intercept & -5.8122 & 0.05791 & 109000 & -100.36 & $<0.0001$ & -5.9257 & -5.6987 \\
\hline & $X_{i 1}$ & -0.00116 & 0.002169 & 109000 & -0.53 & 0.5938 & -0.0054 & 0.00309 \\
\hline & $X_{i 2}$ & 0.01468 & 0.000772 & 109000 & 19.02 & $<0.0001$ & 0.01317 & 0.01619 \\
\hline & $X_{i 3}$ & 0.01139 & 0.001043 & 109000 & 10.92 & $<0.0001$ & 0.00935 & 0.01343 \\
\hline & $X_{i 1} * X_{i 2}$ & 0.000105 & 0.000023 & 109000 & 4.52 & $<0.0001$ & 0.00006 & 0.00015 \\
\hline & $X_{i 2} * X_{i 3}$ & -0.00003 & 0.000012 & 109000 & -2.27 & 0.0235 & -0.00005 & -0.000006 \\
\hline & $X_{i 1} * X_{i 3}$ & -0.00006 & 0.000032 & 109000 & -1.91 & 0.0559 & -0.0001 & 0.000003 \\
\hline \multirow{6}{*}{ ED visit } & Intercept & -7.1008 & 0.1013 & 109000 & -70.07 & $<0.0001$ & -7.2993 & -6.9023 \\
\hline & $X_{i 1}$ & 0.000814 & 0.003466 & 109000 & 0.23 & 0.8143 & -0.006 & 0.00761 \\
\hline & $X_{i 2}$ & 0.01465 & 0.001053 & 109000 & 13.91 & $<0.0001$ & 0.01259 & 0.01671 \\
\hline & $X_{i 3}$ & 0.01126 & 0.001493 & 109000 & 7.55 & $<0.0001$ & 0.00833 & 0.01419 \\
\hline & $X_{i 1} * X_{i 2}$ & 0.000139 & 0.000034 & 109000 & 4.14 & $<0.0001$ & 0.00007 & 0.00021 \\
\hline & $X_{i 1} * X_{i 3}$ & -0.00009 & 0.00005 & 109000 & -1.7 & 0.0886 & -0.0002 & 0.000008 \\
\hline \multirow{7}{*}{ Overall exacerbation } & Intercept & -3.6883 & 0.02589 & 109000 & -142.48 & $<0.0001$ & -3.739 & -3.6376 \\
\hline & $X_{i 1}$ & 0.001349 & 0.000952 & 109000 & 1.42 & 0.1567 & -0.0005 & 0.00321 \\
\hline & $X_{i 2}$ & 0.0128 & 0.000466 & 109000 & 27.5 & $<0.0001$ & 0.01189 & 0.01371 \\
\hline & $X_{i 3}$ & 0.006794 & 0.000665 & 109000 & 10.21 & $<0.0001$ & 0.00549 & 0.0081 \\
\hline & $X_{i 1} * X_{i 2}$ & 0.000046 & 0.000015 & 109000 & 3.09 & 0.002 & 0.000017 & 0.000075 \\
\hline & $X_{i 2} * X_{i 3}$ & -0.00003 & 0.000008 & 109000 & -3.36 & 0.0008 & -0.00005 & -0.00001 \\
\hline & $X_{i 1} * X_{i 3}$ & -0.00005 & 0.000019 & 109000 & -2.74 & 0.0062 & -0.00009 & -0.00001 \\
\hline \multirow{3}{*}{$\begin{array}{l}\text { Ventolin nebulizer } \\
\text { treatment }\end{array}$} & Intercept & -6.5181 & 0.1807 & 109000 & -36.07 & $<0.0001$ & -6.8723 & -6.1639 \\
\hline & $X_{i 1}$ & -0.01108 & 0.008464 & 109000 & -1.31 & 0.1903 & -0.0277 & 0.00551 \\
\hline & $X_{i 2}$ & 0.009296 & 0.004475 & 109000 & 2.08 & 0.0378 & 0.00053 & 0.01807 \\
\hline
\end{tabular}

$X_{i 1}$, total use of asthma medications before pregnancy; $X_{i 2}$, total use of asthma medications during pregnancy; $X_{i 3}$, total use of asthma medications after delivery; ED, emergency department; $\mathrm{DF}$, degree of freedom; $\mathrm{CI}$, confidence interval.

TABLE 10: Possibility of asthma exacerbations during pregnancy explained by asthma medication use in the time period before and during pregnancy.

\begin{tabular}{lcc}
\hline$X_{i 1}$ & $X_{i 2}$ & Possibility of exacerbations \\
\hline Low & High & Likely \\
Low & Low & Possible \\
High & High & Possible \\
High & Low & Uncertain \\
\hline
\end{tabular}

$X_{i 1}$, total use of asthma medications before pregnancy; $X_{i 2}$, total use of asthma medications during pregnancy. 


\section{Abbreviations}

ED: $\quad$ Emergency department

GINA: Global Initiative for Asthma

HIRA: Health Insurance Review and

Assessment Service

ICD: International Statistical Classification of Disease

ICS: $\quad$ Inhaled corticosteroids

ICS/LABA: Inhaled corticosteroids combined with inhaled long-acting $\beta_{2}$-agonists

LABA: $\quad$ Long-acting $\beta_{2}$-agonist

LAMA: Long-acting muscarinic antagonist

LTRA: Oral leukotriene receptor antagonists

SABA: $\quad$ Short-acting $\beta_{2}$-agonist.

\section{Conflicts of Interest}

The authors declare that they have no conflicts of interest.

\section{Authors' Contributions}

So-My Koo and Yunsun Kim contributed equally to this work and should be considered as co-first authors. Sungho Won and Hyeon-Jong Yang contributed equally to this work and should be considered as co-corresponding authors.

\section{Acknowledgments}

This research was supported by a grant from the Korea Health Technology R\&D Project through the Korea Health Industry Development Institute (KHIDI), funded by the Ministry of Health \& Welfare, Republic of Korea (Grant no. HC15C1302). Also, this work was supported by the Soonchunhyang University Research Fund.

\section{References}

[1] V. E. Murphy, V. L. Clifton, and P. G. Gibson, "Asthma exacerbations during pregnancy: incidence and association with adverse pregnancy outcomes," Thorax, vol. 61, no. 2, pp. 169-176, 2006.

[2] H. L. Kwon, K. Belanger, and M. B. Bracken, "Asthma prevalence among pregnant and childbearing-aged women in the United States: estimates from national health surveys," Annals of Epidemiology, vol. 13, no. 5, pp. 317-324, 2003.

[3] V. E. Murphy and P. G. Gibson, "Asthma in pregnancy," Clinics in Chest Medicine, vol. 32, no. 1, pp. 93-110, 2011.

[4] M. Schatz, M. P. Dombrowski, R. Wise et al., "Asthma morbidity during pregnancy can be predicted by severity classification," Journal of Allergy and Clinical Immunology, vol. 112, no. 2, pp. 283-288, 2003.

[5] E. I. Abouleish, T. S. Abboud, G. Bikhazi et al., "Rapacuronium for modified rapid sequence induction in elective Caesarean section: neuromuscular blocking effects and safety compared with succinylcholine, and placental transfer," British Journal of Anaesthesia, vol. 83, no. 6, pp. 862-867, 1999.

[6] S. T. Wilber, J. E. Wilson, M. Blanda, L. W. Gerson, S. O. Meerbaum, and G. Janas, "The bronchodilator effect of intravenous glucagon in asthma exacerbation: a randomized, controlled trial," Annals of Emergency Medicine, vol. 36, no. 5, pp. 427-431, 2000.

[7] S. Kim, J. Kim, S. Y. O. Park et al., "Effect of pregnancy in asthma on health care use and perinatal outcomes," The Journal of allergy and clinical immunology, vol. 136, no. 5, pp. 1215-1223, 2015.

[8] L. J. Tata, S. A. Lewis, T. M. McKeever et al., "Effect of maternal asthma, exacerbations and asthma medication use on congenital malformations in offspring: a UK population-based study," Thorax, vol. 63, no. 11, pp. 981-987, 2008.

[9] L. Blais and A. Forget, "Asthma exacerbations during the first trimester of pregnancy and the risk of congenital malformations among asthmatic women," Journal of Allergy and Clinical Immunology, vol. 121, no. 6, pp. 1379-e1, 2008.

[10] P. A. Zetstra-Van Der Woude, J. S. Vroegop, H. J. Bos, and L. T. W. De Jong-Van Den Berg, "A population analysis of prescriptions for asthma medications during pregnancy," Journal of Allergy and Clinical Immunology, vol. 131, no. 3, pp. 711-717, 2013.

[11] A.-B. Beau, A. Didier, C. Hurault-Delarue, J.-L. Montastruc, I. Lacroix, and C. Damase-Michel, "Prescription of asthma medications before and during pregnancy in France: an observational drug study using the EFEMERIS database," Journal of Asthma, pp. 1-7, 2016.

[12] R. A. Charlton, A. Pierini, K. Klungsoyr et al., "Asthma medication prescribing before, during and after pregnancy: a study in seven European regions," BMJ Open, vol. 6, no. 1, Article ID e009237, 2016.

[13] R. Enriquez, P. Wu, M. R. Griffin et al., "Cessation of asthma medication in early pregnancy," American Journal of Obstetrics and Gynecology, vol. 195, no. 1, pp. 149-153, 2006.

[14] S. H. Kim, B. L. Cho, D. W. Shin et al., "The effect of asthma clinical guideline for adults on inhaled corticosteroids prescriptiontrend: a quasi-experimental study," Journal of Korean Medical Science, vol. 30, no. 8, pp. 1048-1054, 2015.

[15] V. E. Murphy, P. Gibson, P. I. Talbot, and V. L. Clifton, "Severe asthma exacerbations during pregnancy," Obstetrics \& Gynecology, vol. 106, no. 5, Part 1, pp. 1046-1054, 2005.

[16] N. M. Juniper EF, "Effect of pregnancy on asthma: a critical appraisal of the literature," in Asthma and Allergy in Pregnancy snd Early Infancy, M. Schatz and R. S. Zeiger, Eds., pp. 223-249, Marcel Dekker, New York, NY, USA, 1993.

[17] N. M. Juniper EF, "Effect of pregnancy on asthma: a systematic review and meta-analysis," in Asthma and Immunological Diseases in Pregnancy and Early Infancy, M. Schatz, R. S. Zeiger, and H. N. Claman, Eds., pp. 401-427, Marcel Dekker, New York, NY, USA, 1998.

[18] C.-H. Lee, K. Kim, M. K. Hyun, E. J. Jang, N. R. Lee, and J.-J. Yim, "Use of inhaled corticosteroids and the risk of tuberculosis," Thorax, vol. 68, no. 12, pp. 1105-1113, 2013.

[19] Global Initiative for Asthma, "Global strategy for asthma management and prevention," http://ginasthma.org/2017-ginareport-global-strategy-for-asthma-management-and-prevention/.

[20] P. M. O’Byrne, P. J. Barnes, R. Rodriguez-Roisin et al., "Low dose inhaled budesonide and formoterol in mild persistent asthma: the OPTIMA randomized trial," American Journal of Respiratory and Critical Care Medicine, vol. 164, no. 8 I, pp.13921397, 2001.

[21] R. A. Pauwels, S. Pedersen, W. W. Busse et al., "Early intervention with budesonide in mild persistent asthma: a randomised, 
double-blind trial," The Lancet, vol. 361, no. 9363, pp. 1071-1076, 2003.

[22] N. P. Adams, J. B. Bestall, R. Malouf, T. J. Lasserson, and P. W. Jones, "Inhaled beclomethasone versus placebo for chronic asthma," Cochrane Database of Systematic Reviews, no. 1, Article ID CD002738, 2005.

[23] S. Suissa, P. Ernst, S. Benayoun, M. Baltzan, and B. Cai, "Lowdose inhaled corticosteroids and the prevention of death from asthma," New England Journal of Medicine, vol. 343, no. 5, pp. 332-336, 2000.

[24] G. Philip, A. S. Nayak, W. E. Berger et al., "The effect of montelukast on rhinitis symptoms in patients with asthma and seasonal allergic rhinitis," Current Medical Research and Opinion, vol. 20, no. 10, pp. 1549-1558, 2004.

[25] R. Dahl, B. B. Larsen, and P. Venge, "Effect of long-term treatment with inhaled budesonide or theophylline on lung function, airway reactivity and asthma symptoms," Respiratory Medicine, vol. 96, no. 6, pp. 432-438, 2002.

[26] British Thoracic Society Scottish Intercollegiate Guidelines Network, "British guideline on the management of asthma," Thorax, vol. 63, Supplement 4, pp. ivl-iv121, 2008.

[27] F. M. Ducharme, M. Ni Chroinin, I. Greenstone, and T. J. Lasserson, "Addition of long-acting beta2-agonists to inhaled steroids versus higher dose inhaled steroids in adults and children with persistent asthma," Cochrane Database of Systematic Reviews, vol. 4, Article ID CD005533, 2010.

[28] H. Powell and P. G. Gibson, "Inhaled corticosteroid doses in asthma: an evidence-based approach," The Medical Journal of Australia, vol. 178, no. 5, pp. 223-225, 2003.

[29] F. M. Ducharme, M. Ni Chroinin, I. Greenstone, and T. J. Lasserson, "Addition of long-acting beta2-agonists to inhaled corticosteroids versus same dose inhaled corticosteroids for chronic asthma in adults and children," Cochrane Database of Systematic Reviews, vol. 5, Article ID CD005535, 2010.

[30] P. M. O’Byrne, I. P. Naya, A. Kallen, D. S. Postma, and P. J. Barnes, "Increasing doses of inhaled corticosteroids compared to adding long-acting inhaled $\beta 2$-agonists in achieving asthma control," Chest, vol. 134, no. 6, pp. 1192-1199, 2008.

[31] G. J. Rodrigo and J. A. Castro-Rodríguez, "What is the role of tiotropium in asthma?: a systematic review with meta-analysis," Chest, vol. 147, no. 2, pp. 388-396, 2015.

[32] K. F. Chung, S. E. Wenzel, J. L. Brozek et al., "International ERS/ATS guidelines on definition, evaluation and treatment of severe asthma," European Respiratory Journal, vol. 43, no. 2, pp. 343-373, 2014.

[33] L. Smy, A. C. Chan, P. Bozzo, and G. Koren, "Is it safe to use inhaled corticosteroids in pregnancy?" Canadian Family Physician, vol. 60, no. 9, Article ID e433-805, pp. 809-812, 2014.

[34] M. Schatz, M. P. Dombrowski, R. Wise et al., "The relationship of asthma medication use to perinatal outcomes," Journal of Allergy and Clinical Immunology, vol. 113, no. 6, pp. 1040-1045, 2004.

[35] R. A. Charlton, J. M. Snowball, A. L. Nightingale, and K. J. Davis, "Safety of fluticasone propionate prescribed for asthma during pregnancy: a UK population-based cohort study," Journal of Allergy and Clinical Immunology: In Practice, vol. 3, no. 5, pp. 772-779.e3, 2015. 


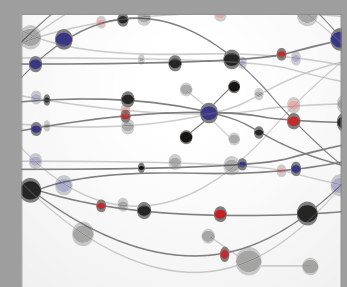

The Scientific World Journal
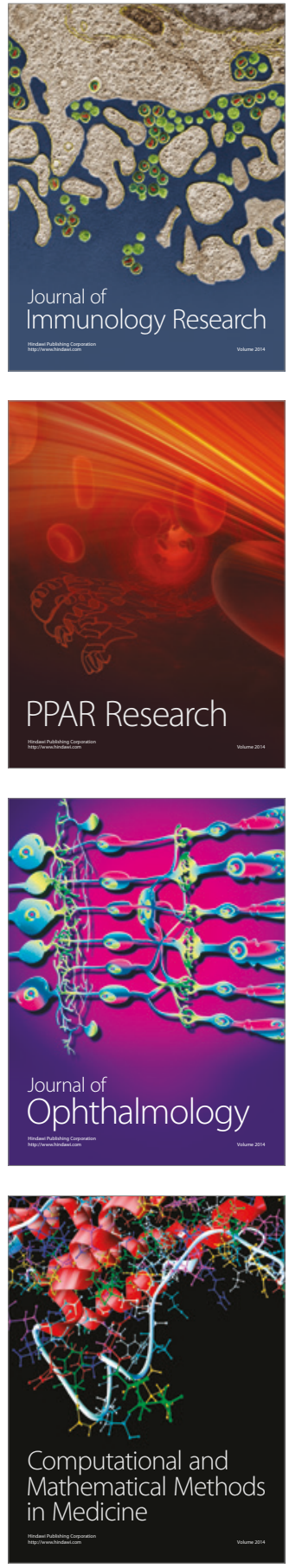

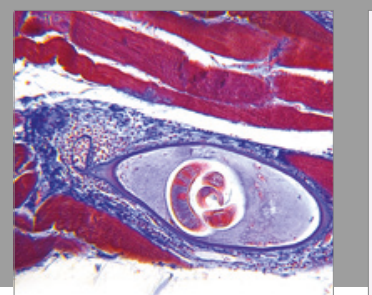

Gastroenterology Research and Practice
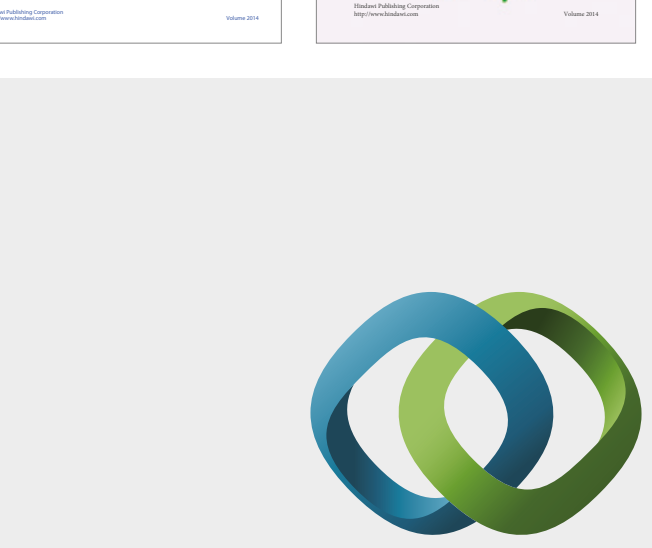

\section{Hindawi}

Submit your manuscripts at

https://www.hindawi.com
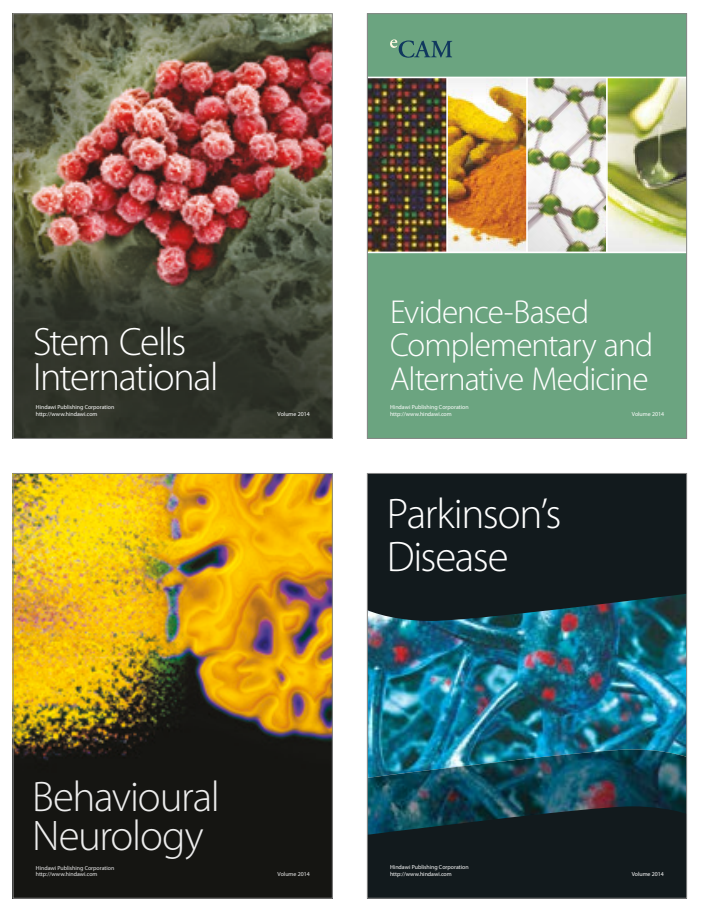
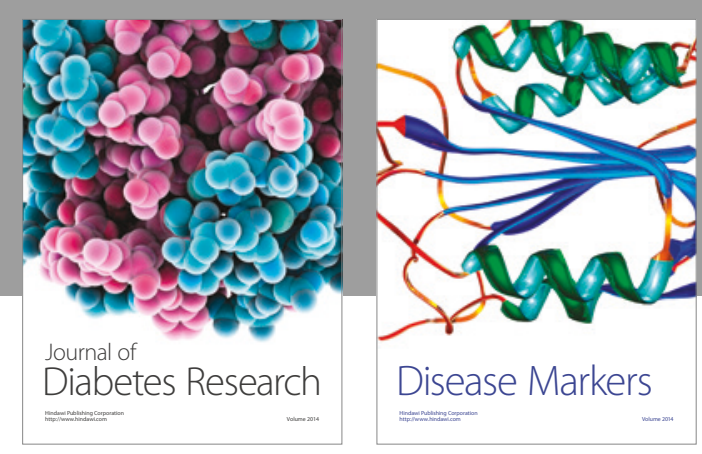

Disease Markers
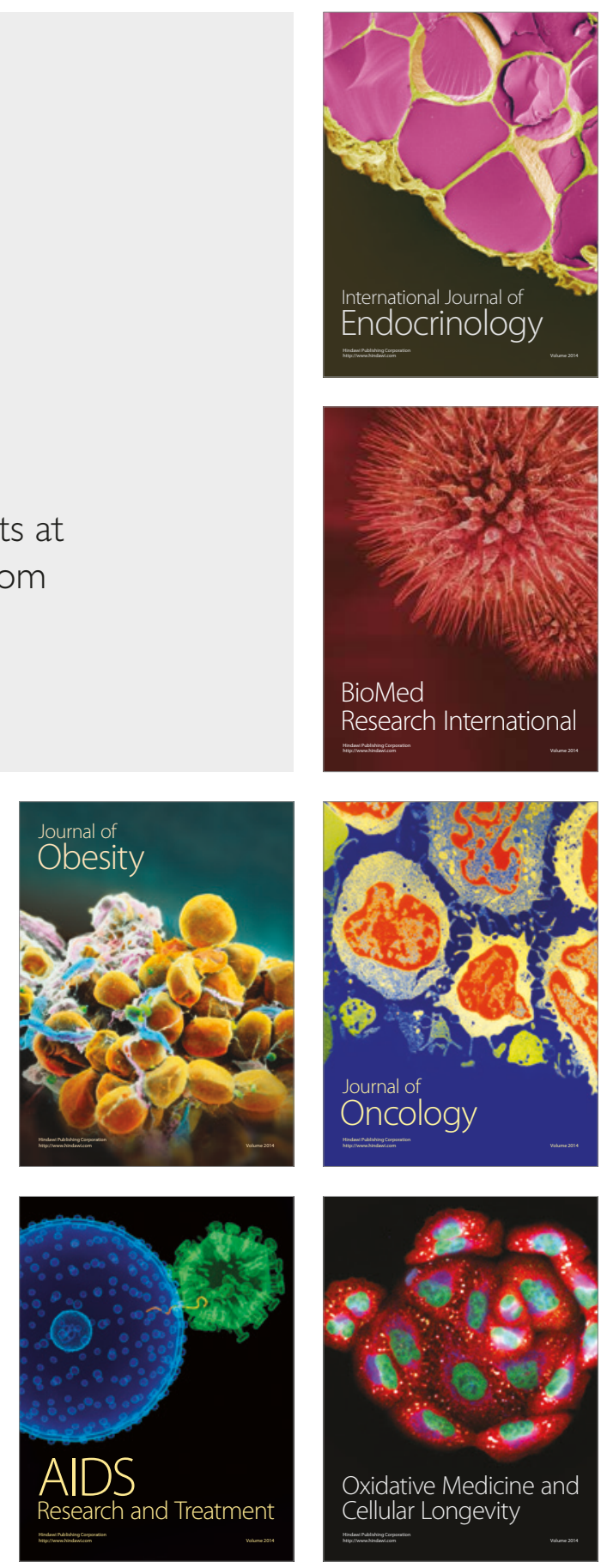